\section{Emericellin, a New Metabolite from Aspergillus nidulans}

\author{
Masayoshi IsHIDA, Takashi HAMASAKI, ${ }^{1 *}$ \\ Yuichi HatsUda, ${ }^{*}$ Keiichi FukUyama, ${ }^{2 *}$ \\ Tomitake TsUkIHARA* and \\ Yukiteru KATSUBE ${ }^{2 *}$ \\ Tottori Women's College, Kurayoshi, Tottori \\ ${ }^{1 *}$ Faculty of Agriculture, Tottori \\ University, Tottori \\ ${ }^{2 *}$ Faculty of Engineering, Tottori \\ University, Tottori \\ Received Nobember 5, 1974
}

We reported on a new metabolite, emerin, of Aspergillus nidulans (Eidam) Winter and the production of sterigmatocystin, averufin and versicolorin $\mathrm{C}$ in this mold. ${ }^{11}$ In continuation of our work on the metabolites of this mold we have isolated some new metabolites from the mycelia and one of them has been named emericellin. This metabolite has been also isolated from the mycelia of Aspergillus rugulosus Thom et Raper and Aspetgillus quadrilineatus Thom et Raper. In this paper we wish to report on the isolation method and chemical structure of emericellin.

This mold was cultivated on the malt extract medium at $25^{\circ} \mathrm{C}$ and the mycelial mat was harvested after 3 weeks. The dried mycelial mat was extracted with benzene and the isolation of emericellin from the benzene extract was achieved by the chromatography on a column of silica gel.

Emericellin (I) crystallized from ethanol in yellow prisms, $\mathrm{mp} 110 \sim 112^{\circ} \mathrm{C},[\alpha]_{\mathrm{D}}=0$. Anal. Found: $\mathrm{C}, 73.15 ; \mathrm{H}, 6.87 ; \mathrm{m} / \mathrm{e}: 408\left(\mathrm{M}^{+}\right)$. Calcd. for $\mathrm{C}_{25} \mathrm{H}_{28} \mathrm{O}_{5}: \mathrm{C}, 73.51 ; \mathrm{H}, 6.91 \%$; M.W., 408. UV $\lambda_{\max }^{\text {EtoH }} \mathrm{nm}(\varepsilon): 238$ (30800), 267 (32200), 272 (32700), 295 (10000), 384 (5600). It gave a dark green color with ethanolic ferric chloride. Acetylation of I with acetic anhydride and anhydrous sodium acetate gave a diacetate (II), $\mathrm{mp} 103 \sim 104^{\circ} \mathrm{C}$. Anal. Found: C, 70.17; H, 6.49. Calcd. for $\mathrm{C}_{28} \mathrm{H}_{32} \mathrm{O}_{7}$ : C, 70.71; $\mathrm{H}, 6.55 \%$. Its IR spectrum showed the bands at 1760 and 1742 $\mathrm{cm}^{-1}$ indicating the formation of phenolic and aliphatic acetyl groups. Methylation of I with methyl iodide and potassium carbonate gave a monomethyl ether (III), mp $99 \sim 101^{\circ} \mathrm{C}$. Anal. Found: C, 73.75; H, 7.15. Calcd. for $\mathrm{C}_{26} \mathrm{H}_{30} \mathrm{O}_{5}: \mathrm{C}, 73.91 ; \mathrm{H}, 7.16 \%$.

Degradation of I with aluminium chloride in chlorobenzene gave a pale yellow phenolic compound (IV), mp $265^{\circ} \mathrm{C}$ (decomp.). Anal. Found: $\mathrm{C}, 69.53 ; \mathrm{H}, 4.20 ; \mathrm{m} / \mathrm{e}: 242\left(\mathrm{M}^{+}\right)$. Calcd. for $\mathrm{C}_{14} \mathrm{H}_{10} \mathrm{O}_{4}$ : C, 69.42; H, 4.16\%; M.W., 242. UV $\lambda_{\max }^{\mathrm{EtOH}} \mathrm{nm}(\varepsilon): 234 \quad(24400), 245$ (29500), 256 (29800), 287 (11900), 383 (8800). Its UV spectrum was characteristic of xanthone. It gave a dark green color with ethanolic ferric chloride. The NMR spectrum of IV showed the signals of aromatic methyl proton at $\delta 2.31$ $(3 \mathrm{H}$, singlet), five aromatic protons at $\delta 6.74$ $(1 \mathrm{H}$, doublet of doublets, $J=1$ and $8 \mathrm{~Hz}$ ), $6.95(1 \mathrm{H}$, doublet of doublets, $J=1$ and $8 \mathrm{~Hz}$ ), 7.34 (1H, singlet), $7.46(1 \mathrm{H}$, singlet) and 7.66 ( $1 \mathrm{H}$, triplet, $J=8 \mathrm{~Hz}$ ), hydrogen bonded phenolic hydroxy proton at $\delta 12.76(1 \mathrm{H}$, singlet) and phenolic hydroxy proton at $\delta 3.35(1 \mathrm{H}$, singlet). These spectral data suggested that IV may be 1,7-dihydroxy-6-methylxanthone.

To confirm the structure of IV, this compound was synthesized by condensation of 2,5-dihydroxy-4-methylbenzoic acid and resorcinol in the presence of phosphoryl chloride and zinc chloride. Comparison of IV and synthetic compound assured their identity.

In the NMR spectrum of I two signals at $\delta 4.35(1 \mathrm{H}$, triplet, $J=8 \mathrm{~Hz})$ and $12.50(1 \mathrm{H}$, singlet) were disappeared by addition of deuterium oxide and assigned to the primary hydroxy and hydrogen bonded phenolic hydroxy protons. The signal at $\delta 7.28(1 \mathrm{H}$, singlet) which showed the weak long range coupling with the signal of aromatic methyl proton $(\delta 2.45,3 \mathrm{H}$, singlet) was assigned to the proton at the position 5 in xanthone nucleus. The signals at $\delta 6.68(1 \mathrm{H}$, doublet, $J=8.5 \mathrm{~Hz})$ and $7.40(1 \mathrm{H}$, doublet, $J=8.5 \mathrm{~Hz})$ were assigned to the protons at the position 2 and 3 , or 4 and 3 . Emericellin is, therefore, either 4,7,8- or 2,7,8-trisubstituted 1-hydroxy-6-methylxanthone. The signals at $\delta 1.75 \sim 1.80(3 \mathrm{H} \times 4)$ 
were assigned to the protons of four olefinic methyl groups. The signals at $\delta 4.44(2 \mathrm{H}$, doublet, $J=7 \mathrm{~Hz})$ and $5.62(1 \mathrm{H}$, triplet, $J=$ $7 \mathrm{~Hz}$ ) were assigned to the methylene proton attached to the oxygen-bearing carbon and olefinic proton, respectively. These data indicate the presence of $\mathrm{O}$-isoprenyl group in $\mathrm{I}$. The signals at $\delta 3.47(2 \mathrm{H}$, doublet, $J=7 \mathrm{~Hz})$ and $5.31(1 \mathrm{H}$, triplet, $J=7 \mathrm{~Hz})$ were assigned to the methylene and olefinic protons of Cisoprenyl group.

Cyclization of I with formic acid was not observed. Moreover, the methylene proton ( $\delta$ 3.47) of C-isoprenyl group was found to be weakly coupled with the aromatic proton $(\delta 7.40)$. From these evidences it is considered that $\mathrm{C}$-isoprenyl group is located at the position 4 in xanthone nucleus. Consequently, the hydroxymethyl group is located at the position 8 in xanthone nucleus. Therefore, the structure for emericellin may be 1-hydroxy-4-(3-methyl2-butenyl)-6-methyl-7-(3-methyl-2-butenyloxy)-8-hydroxymethylxanthone.

The structure of I was confirmed by means of X-ray diffraction method. Electron density map of emericellin is shown in Fig. 1. The details of X-ray analysis will be published in near future. ${ }^{2 !}$

Acknowledgement. We wish to thank Dr. G. Sunagawa, Central Research Laboratory, Sankyo Co., Ltd., for the elemental analysis and measurement of NMR and mass spectra.<smiles>[R10]Cc1c(OCC=C(C)C)c(C)cc2oc3c(CC=C(C)C)ccc(O[R17])c3c(=O)c12</smiles>

$$
\begin{array}{rrrr} 
& \text { I } & \text { II } & \text { III } \\
\mathrm{R}_{1} & \mathrm{H} & \mathrm{Ac} & \mathrm{Me} \\
\mathrm{R}_{2} & \mathrm{H} & \mathrm{Ac} & \mathrm{H}
\end{array}
$$

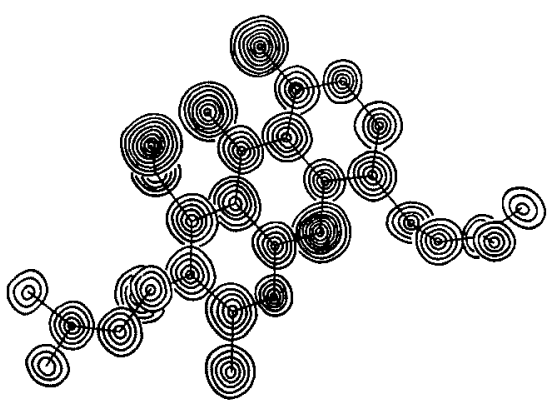

FIG. 1. Electron Density Map of Emericellin.

\section{REFERENCES}

1) M. Ishida, T. Hamasaki and Y. Hatsuda, Agr. Biol. Chem., 36, 1847 (1972).

2) Some of this work will be presented at the Meeting of Chemical Society of Japan in Tottori, November, 1974. 